\title{
AN OBSERVATIONAL STUDY ON ACUTE POISONING IN PAEDIATRIC POPULATION IN A RURAL MEDICAL COLLEGE.
}

\section{Pediatrics \\ Madhunandan \\ Krishnegowda* \\ Assistant Professor, Department of Paediatrics, Adichunchanagiri Institute of Medical Sciences, Mandya, Karnataka, India. *Corresponding Author \\ Rohan Yadav \\ Junior Resident, Department of Paediatrics, Adichunchanagiri Institute of Medical Sciences, Mandya, Karnataka, India.}

\section{ABSTRACT}

Backgound: In paediatric emergencies acute poisoning is frequently encountered and is the leading cause of morbidity and mortality in developing countries. There is natural division of acute poisoning in paediatric population in to two groups i.e. young children and adolescents. The first group comprises of young children who innocently ingest small amount of single substances. Second group comprises of adolescents who purposefully ingest substantial quantity of multiple substances secondary to emotional outburst or psychiatric illness. This study aimed to study the clinical, toxicological profile and outcome of Acute poisoning in paediatric population in Adichunchanagiri institute of medical sciences, Mandya, Karnataka, India.

Subjects And Methods: This is a retrospective observational study done from January 2018- December 2019, in Adichunchanagiri institute of medical sciences, Mandya, Karnataka, India, involving childhood poisoning. Data was noted on a predesigned proforma, it was compiled and entered in MS Excel spread sheet; descriptive statistics was applied.

Results: Out of 50 cases 24 cases (48\%) were males and 26 cases (52\%) were females. Majority of cases were distributed in the age group of 1-4 years 24 cases (48\%), followed by $15-18$ years 19 cases (38\%). Suicidal poisoning was more seen in adolescent females 15 cases (30\%). Pesticide and insecticide remains the most common toxic agent i.e. 21 cases $(42 \%)$, followed by hydrocarbons 16 cases $(32 \%)$. 42 cases $(84 \%)$ got improved, 5 cases $(10 \%)$ got referred and there was $1(2 \%)$ death. Majority of the cases (52\%) got discharged between 1-3 days.

Conclusions: Pesticides and hydrocarbons remains most easily accessible toxins in rural area hence, are most commonly implicated toxins in childhood poisoning. Though poisoning remains worrisome problem, it is preventable.

\section{KEYWORDS}

Paediatric poisoning, Accidental poisoning, Pesticides, Hydrocarbons.

\section{BACKGROUND}

Poisoning is defined as exposure of an individual to a substance that can cause symptoms and signs of organ dysfunction leading to injury or death ${ }^{1}$. Poison is a substance which is harmless in small quantities and may cause death when taken in large amount ${ }^{2}$.

In paediatric emergencies acute poisoning is frequently encountered and is the leading cause of morbidity and mortality in developing countries ${ }^{3}$.There is natural division of acute poisoning in paediatric population in to two groups i.e. young children and adolescents. The first group comprises of young children who innocently ingest small amount of single substances. Second group comprises of adolescents who purposefully ingest substantial quantity of multiple substances secondary to emotional outburst or psychiatric illness ${ }^{4}$.

The nature of a child is to explore the surrounding environment. As children acquire developmental milestones, they learn to become independent and tend to explore surroundings. Toddlers and preschoolers are more prone for accidental poisoning as they are under the influence of growth and development.

Toddlers will undergo refinement of previously acquired gross and fine motor skills. On encountering new situation toddlers start experimenting with their newly refined skills which is considered normal, but can put a child into a dangerous situation if such behaviour gets unseen by adults ${ }^{5}$. Taste sensation in toddlers is not mature enough to identify unpalatable substances which results in consumption of substantial amount of unpalatable products ${ }^{6}$. Things which are regarded as dangerous or unwanted by adults will be perceived as interesting by children.

Curiosity of preschool children towards environment increases. A child learns to speak a word before understanding its meaning i.e. without understanding the meaning of the word poison; child may be able to pronounce it. Pre-schoolers have inability to differentiate medications from food, which can lead to accidental ingestion of medications as many of them are manufactured in tasty flavours and attractive colours ${ }^{7}$.

Older children and adolescents are more vulnerable for intentional poisoning because of impulsivity, peer pressure, emotional outburst which is more common in this age group ${ }^{8,9}$. They ingest larger amounts and at times multiple toxins ${ }^{10}$.

\section{SUBJECTS AND METHODS}

Aims And Objective:

To study the clinical, toxicological profile and outcome of acute poisoning in paediatric population.

Source Of Data:

\begin{tabular}{|l|l|}
\hline STUDY PLACE & $\begin{array}{l}\text { Study was conducted in Rural teaching } \\
\text { hospital Adichunchanagiri Institute of } \\
\text { medical sciences, Mandya district }\end{array}$ \\
\hline STUDY DURATION & January 2018- December 2019 \\
\hline STUDY SUBJECTS & $\begin{array}{l}\text { Cases of acute poisoning in Paediatric age } \\
\text { group (0-18 years) }\end{array}$ \\
\hline STUDY DESIGN & Retrospective observational study \\
\hline STUDY SIZE & $\begin{array}{l}\text { All Paediatric cases which presented with } \\
\text { acute poisoning }\end{array}$ \\
\hline
\end{tabular}

\section{Inclusion Criterion-}

Any paediatric case with history of acute poisoning or clinical symptoms and signs suggestive of acute poisoning.

\section{Exclusion Criterion-}

Cases with food poisoning, drug reactions, animal/insect bites and chronic poisoning.

\section{Method Of Collection Of Data}

We studied the clinical presentation, treatment methods, and outcome of Paediatric patients who met the inclusion criteria. Data for the study was collected from inpatient case sheets. Data regarding age, sex, place, type of the poison, time of ingestion, intent, time of presentation to hospital, symptoms and signs, investigations, diagnostic and therapeutic interventions, and outcome were noted on a predesigned proforma.

\section{Statistical Analysis-}

Data thus obtained was compiled and entered in MS Excel spread sheet; descriptive statistics was applied, cross tables were constructed, data was expressed in terms of frequency and percentage.

\section{RESULTS}

During study period a total of 867 cases got admitted to our Paediatric ICU out of which 50 cases came under inclusion criteria. This accounted for $5.7 \%$ of Paediatric ICU admissions. Out of 50 cases 24 cases $(48 \%)$ were males and 26 cases $(52 \%)$ were females. There was almost equal distribution of cases among males and females (Figure 1). 


\section{GENDER}

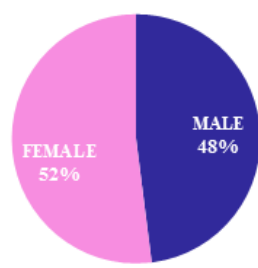

\section{Figure 1: Gender Distribution Of Cases}

When age distributions of cases were seen (Figure 2) majority of cases were distributed in the age group of 1-4 years i.e. 24 cases (48\%), followed by $15-18$ years i.e. 19 cases (38\%). Though there was over all equal distribution of cases, there was slight male preponderance in 1-4 year age group and notably higher incidence for females in 15-18 year group.

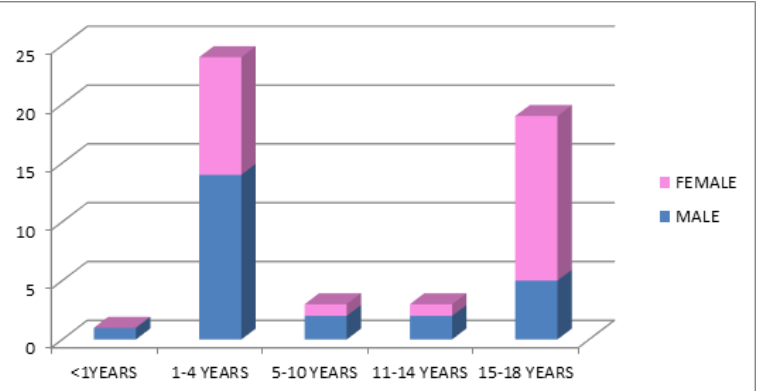

Figure 2: Age Distribution Of Cases.

Time taken to reach hospital from the time of incident was noted (Table 1). Our findings showed maximum number of cases (64\%) reached the hospital between 1- 4 hours after the incident, this time frame is important because earlier the intervention better is the outcome. Majority of the poisoning in our study were indoor i.e. 47 cases (94\%), Accidental poisonings were more common (Table 2), 31 cases (62\%), compared to suicidal which were 19 (38\%). Poison with suicidal intent was never seen in children less than 10 years. Suicidal poisoning was more seen in adolescent females 15 cases $(30 \%)$.

Table 1: Time Taken To Reach Hospital

\begin{tabular}{|l|l|}
\hline TIME & NUMBER \\
\hline$<1$ HOUR & $9(18 \%)$ \\
\hline $1-4$ HOURS & $32(64 \%)$ \\
\hline$>4$ HOURS & $9(18 \%)$ \\
\hline
\end{tabular}

Table 2: Comparison Of Nature Of Poison With Age Distribution

\begin{tabular}{|l|l|l|l|l|l|}
\hline \multirow{2}{*}{ AGE } & \multicolumn{2}{|l|}{ ACCIDENTAL } & \multicolumn{2}{|l|}{ SUICIDAL } & TOTAL \\
\cline { 2 - 5 } & MALE & FEMALE & MALE & FEMALE & \\
\hline <1 YEARS & 1 & 0 & 0 & 0 & $1(2 \%)$ \\
\hline 1-4 YEARS & 15 & 9 & 0 & 0 & $24(48 \%)$ \\
\hline 5-10 YEARS & 2 & 1 & 0 & 0 & $3(6 \%)$ \\
\hline 11-14 YEARS & 0 & 0 & 2 & 1 & $3(6 \%)$ \\
\hline 15-18 YEARS & 2 & 1 & 2 & 14 & $19(38 \%)$ \\
\hline TOTAL $(\mathrm{M}+\mathrm{F})$ & $31(62 \%)$ & \multicolumn{2}{|l|}{$19(38 \%)$} & $50(100 \%)$ \\
\hline
\end{tabular}

On presentation (Table 3), majority of cases had vomiting which was noted in 30 cases $(60 \%)$, followed by pain abdomen in $38 \%$ of cases. $26 \%$ of cases were asymptomatic. Respiratory distress was present in $22 \%$ of cases. Drowsiness, loss of consciousness and convulsions were also seen

Table 3: Symptoms Among The Cases

\begin{tabular}{|l|l|}
\hline SYMPTOMS & NUMBER \\
\hline VOMITTING & 30 \\
\hline PAIN ABDOMEN & 19 \\
\hline ASYMPTOMATIC & 13 \\
\hline RESPIRATORY DISTRESS & 11 \\
\hline DROWSINESS & 6 \\
\hline LOSS OF CONSCIOUSNESS & 4 \\
\hline CONVULSIONS & 3 \\
\hline
\end{tabular}

Various toxic agents were seen in this present study (Table 4). Hydrocarbons, insecticides and pesticides, drugs, detergents and unknown substances were toxic agents in our study. Pesticide and insecticide remain the most common toxic agent i.e. 21 cases $(42 \%)$. Followed by hydrocarbons 16 cases (32\%). Hydrocarbons were seen exclusively as accidental poison. Out of 21 cases of pesticide poison majority 13 cases $61.9 \%$ were with suicidal intent. Children consuming multiple tablets which were available to them easily at home were also seen in 2 cases, this was with an intention of committing suicide, as a result of emotional outburst.

Table 4: Comparison Of Various Toxic Agents With Nature Of Poisoning And Gender.

\begin{tabular}{|c|c|c|c|c|c|}
\hline & \multicolumn{2}{|c|}{ ACCIDENTAL } & \multicolumn{2}{|c|}{ SUICIDAL } & TOTAL \\
\hline & MALE & FEMALE & MALE & FEMALE & \\
\hline $\begin{array}{l}\text { 1.HYDROCARB } \\
\text { ONS }\end{array}$ & 11 & 5 & O & $\mathbf{0}$ & \multirow[t]{6}{*}{$\begin{array}{l}16 \\
(32 \%)\end{array}$} \\
\hline a. Turpentine oil & 1 & 2 & 0 & 0 & \\
\hline b. Kerosene & 7 & 3 & 0 & 0 & \\
\hline c. Petrol & 1 & 0 & 0 & 0 & \\
\hline d. Camphor & 1 & 0 & 0 & 0 & \\
\hline e. Moth ball & 1 & 0 & 0 & 0 & \\
\hline 2.UNKNOWN & 2 & $\mathbf{0}$ & $\mathbf{0}$ & $\mathbf{0}$ & $2(4 \%)$ \\
\hline \begin{tabular}{|l|} 
3.INSECTICIDE \\
AND PESTICIDE
\end{tabular} & 4 & 4 & 3 & 10 & \multirow[t]{4}{*}{$\begin{array}{l}21 \\
(42 \%)\end{array}$} \\
\hline a. OP Compound & 1 & 1 & 3 & 7 & \\
\hline b. Pyrethroid & 1 & 1 & 0 & 3 & \\
\hline $\begin{array}{l}\text { c. Aluminium } \\
\text { phosphide }\end{array}$ & 2 & 2 & 0 & 0 & \\
\hline 4.DRUGS & 1 & 1 & $\mathbf{0}$ & 5 & \multirow[t]{6}{*}{$7(14 \%)$} \\
\hline a. Alprazolam & 1 & 0 & 0 & 1 & \\
\hline b. Phenobarbitone & 0 & 0 & 0 & 1 & \\
\hline c. Paracetamol & 0 & 0 & 0 & 1 & \\
\hline d. Levocetirizine & 1 & 1 & 0 & 0 & \\
\hline e. Multiple tablets & 0 & 0 & 0 & 2 & \\
\hline 5. DETERGENTS & 2 & 1 & 1 & 0 & $4(8 \%)$ \\
\hline TOTAL $(\mathrm{M}+\mathrm{F})$ & \multicolumn{2}{|c|}{$31(62 \%)$} & \multicolumn{2}{|c|}{$19(38 \%)$} & \begin{tabular}{|l|l|}
50 \\
$(100 \%)$
\end{tabular} \\
\hline
\end{tabular}

Outcome of the disease was assessed in terms of improved, referred, death and discharged against medical advice, 42 cases (84\%) got improved, 5 cases $(10 \%)$ got referred, $2(4 \%)$ cases got discharged against medical advice and there was $1(2 \%)$ death (Table 5$)$. Majority of the cases (52\%) got discharged between 1-3 days (Table 6).

Table 5: Outcome Of Cases.

\begin{tabular}{|l|l|}
\hline OUTCOME & NUMBER \\
\hline IMPROVED & $42(84 \%)$ \\
\hline REFFERED & $5(10 \%)$ \\
\hline DAMA & $2(4 \%)$ \\
\hline DEATH & $1(2 \%)$ \\
\hline
\end{tabular}

\section{Table 6: Duration Of Hospital Stay.}

\begin{tabular}{|l|l|}
\hline DURATION & NUMBER \\
\hline$<1$ DAY & $6(12 \%)$ \\
\hline $1-3$ DAYS & $26(52 \%)$ \\
\hline$>3$ DAYS & $18(36 \%)$ \\
\hline
\end{tabular}

\section{DISCUSSION}

Poisoning is a significant worldwide general medical issue. The problem magnitude varies from country to country. In countries like USA which are developed, poisoning constitutes an important part of emergency care spectrum ${ }^{11}$. This situation remains same even in developing countries like India. We aimed to study the clinical, toxicological profile and outcome of Acute poisoning in paediatric population. We had a total case of 50 , with respect to gender preponderance, there was overall almost equal distribution cases among males and females 24 and 26 respectively but when age factor was taken into consideration, incidence was more common in boys in younger age group, whereas it was more common in girls in adolescent age group, similar findings were seen in study done by Devaranavadagi et a $1^{12}$

In our study maximum cases were seen in the age group between 1-4 years i.e. 24 cases $(48 \%)$ similar preponderance were observed in other studies ${ }^{3,13-15}$. Few studies reported incidence being more in older children i.e. children more than 10 years ${ }^{12,16}$. 
Our findings showed maximum number of cases $(64 \%)$ reached the hospital between 1- 4 hours after the incident. A study done by Aqeel et al reported maximum number of cases reached hospital between 1 and 6 hours of poisoning ${ }^{17}$. Another study by Ahmed et al reported maximum number of the cases $(80 \%)$ reached to hospital less than 1 hour of incident ${ }^{18}$.

They presented with various clinical presentations like vomiting, pain abdomen, respiratory distress, drowsiness, loss of consciousness, convulsions and few were asymptomatic. Majority of them had vomiting 30 cases $(60 \%)$. Similar observations were made in Devaranavadagi RA et $\mathrm{al}^{12}$ and Sharma J et $\mathrm{al}^{16}$.

In our study most common toxic agent is pesticide ( $42 \%)$ followed by hydrocarbons $(32 \%)$. Pesticides were the common toxic agents of poison in a study conducted by Shashidhar V et al ${ }^{19}$ and Budhathoki $\mathrm{S}^{20}$. Other studies by Shridhar PV et $\mathrm{al}^{21}$ and Kariyappa $\mathrm{M}$ et $\mathrm{al}^{22}$ showed kerosene to be the most common agent.

Majority of the cases in our study had hospital stay between 1-3 days. We had one mortality, which was a due to pesticide ingestion (organophosphorus compound) remaining other cases survived including discharged against medical advice and referred cases.

From the above study we can conclude that, pesticides and kerosene (hydrocarbon) remains most easily accessible toxins in rural area hence, they remain the most commonly implicated toxins in childhood poisoning. Though poisoning remains worrisome problem, it is preventable. Following measures can be taken to prevent it.

1. Keeping the toxic substances out of reach of children.

2. Creating awareness about poison among parents and children through health education.

3. Proper disposal of poisonous substances.

4. Having child counsellor in every school for guidance, which helps in prevention of suicidal poisoning.

5. Conducting workshops on good parenting skills.

\section{Financial Support And Sponsorship Nil}

\section{Acknowledgement}

We thank the Medical Records Department for providing us with the records needed for this study.

\section{Conflict Of Interest}

There are no conflicts of interest.

\section{REFERENCES}

1. CDC. Poisoning among young children - United States. MMWR 1984;33:129-31

2. Narayan Reddy K.S., Murthy O.P. The essential of Forensic Medicine and Toxicology, 33rd edition, The Health Sciences Publishers. 2014;498-519.

3. Gupta SK, Peshin SS, Srivastava A, Kaleekal T. A study of childhood poisoning at National Poisons Information Centre, All India Institute of Medical Sciences, New Delhi. J Occup Health 2003;45:191-6.

4. Choudhury P, Bagga A, Chugh K, Ramji S, Gupta P. Principles of pediatric and neonatal emergencies, $3^{\text {rd }}$ edition, Jaypee publishers. 2011;459-64.

5. Wilkerson R, Northingson LD, Fisher W. Ingestion of toxic substances by infants and children. What we don't know can hurt. Crit Care Nurse. 2005;25:35-44

6. James S, Ashwill J, Droske S. Nursing Care of Children: Principles and Practice.2nd ed. Philadelphia, Pa: WB Saunders Co; 2002.

7. Hockenberry M. Wong's Nursing Care of Infants and Children.7th ed. St Louis, Mo: Mosby; 2003

8. Dutta AK, Seth A, Goyal PK, Agarwal V, Mittal SK, Sharma R et al. Poisoning in children, Indian scenario. Indian J Pediatr. 1998;65:365-70.

9. Krishankumar P, Geeta MG, Gopalan AV. Deliberate Self-Poisoning in Children. Indian Pediatr. 2005;42:582-6.

10. Ranjit S. Manual of pediatric emergencies and critical care, $2^{\text {nd }}$ edition. Paras medical publisher. 2015,362-6.

11. Litovitz TL, Klein-Schwartz W, Rodgers GC. Annual report of American association of poison control canters toxic exposure surveillance system. Am J Emerg Med 2002; 20: 391-452.

12. Devaranavadagi RA, Patel S, Shankar P. A study on profile of poisoning in pediatric population. Int J Contemp Pediatr 2017;4:810-5

13. Bhat NK, Dhar M, Ahmad S, Chandar V. Profile of poisoning in children and adolescents at a North Indian tertiary care centre. JIACM. 2011;13:37-42

14. Kohli U, Kuttait VS, Lodha R, Kabra SK. Profile of Childhood Poisoning at a Tertiary Care Centre in North India. Indian J Pediatrics. 2008;75:791-4.

15. Akhtar S, Rani GR, Al-Anezi FA. Risk factors in acute poisoning in children-A retrospective study. Kuwait Med J. 2006;38(1):33-6.

16. Sharma J, Kaushal RK. Profile of poisoning in children. Pediatric Oncall. 2014;11:40-2

7. Aqeel M, Munir A, Khan A. Paern and frequency of acute poisoning in children. Pak J Aqeel M, Munir A, Khan A. Paern and frequency of acute poisoning in children. Pak J
Med Sci 2009;25(3):479-83.

18. Ahmed A, Aljamal A, Ibrahim M. Poisoning emergency visits among children: A 3-year retrospective study in Qatar. BMC Pediatr. 2015;15,104:1-7.

19. Shashidhar V, Yogesh G. Profile of Pediatric Poisoning at District Hospital Gulbarga. Int J Med Res Rev. 2013;1(5):245-9.

20. Budhathoki S, Poudel P, Shah D, Bhatta NK, Dutta AK, Shah GS. Clinical profile and outcome of children presenting with poisoning or intoxication: a hospital based study.
Nepal Med Coll J. 2009;11(3):170-5.

21. Sridhar PV, Sandeep M, Thammanna PS. Clinical profile and outcome of poisoning in pediatric age group at a tertiary care teaching hospital, Mandya, Karnataka, India. Int J Contemp Pediatr. 2016 May;3(2):514-17

22. Kariyappa M, Benakappa A, Kejjaiah A, Ramachandrappa RS. Spectrum of Poisoning in Children: Study from Tertiary Care Hospital in South India. Journal of Evidence based Medicine and Healthcare; 2015;33(2): 4989-99. 